\title{
Should sustainability and resilience be combined or remain distinct pursuits?
}

\author{
Charles L. Redman $^{1}$
}

ABSTRACT. It has become common for sustainability science and resilience theory to be considered as complementary approaches. Occasionally the terms have been used interchangeably. Although these two approaches share some working principles and objectives, they also are based on some distinct assumptions about the operation of systems and how we can best guide these systems into the future. Each approach would benefit from some scholars keeping sustainability science and resilience theory separate and focusing on further developing their distinctiveness and other scholars continuing to explore them in combination. Three areas of research in which following different procedures might be beneficial are whether to prioritize outcomes or system dynamics, how best to take advantage of community input, and increasing the use of knowledge of the past as a laboratory for potential innovations.

Key Words: adaptation; adaptive capacity; resilience theory; sustainability science; transformation

\section{INTRODUCTION}

To advance understanding of how best to accomplish maximum good for society and the environment, many researchers are attempting to combine the concepts and theoretical approaches of sustainability science and resilience theory. A recent Ecology and Society article by Anderies and others (2013) suggests creative solutions to the problem of blending these concepts. However, these and other suggested solutions could inadvertently compromise fundamental assumptions of the respective theories. I strongly advocate ideas drawn from sustainability science as defined by Kates et al. (2001), Clark and Dickson (2003), Gibson (2006), and Weik et al. (2011), and from resilience theory as summarized by Gunderson and Holling (2002) in Panarchy, clearly communicated by Walker and Salt (2006) in Resilience Thinking, and specified in many articles in Ecology and Society. I have been a member of the Resilience Alliance for more than 12 years and have advocated that framework often (Redman and Kinzig 2003, Redman 2005). In addition, for the past ten years I have been charged with developing sustainability research, education, and solutions at Arizona State University, serving as the first director of the Global Institute of Sustainability and then of the School of Sustainability (Miller et al. 2011, Redman 2013, Redman and Wiek 2013). My experiences interacting with leading voices in the Resilience Alliance and the sustainability-science community have strongly colored the perspective I take in this article.

Given these dual influences, it is not surprising that I considered combining these approaches in my own work, which led me to present an invited paper on urban sustainability at the Resilience 2011 conference in Tempe, Arizona. As I prepared that paper, I came to realize that fundamental assumptions within each approach differed and even contradicted each other. For example, one commonly invoked outcome for sustainable city is maximum efficiency via minimizing energy and material use, but that positive outcome could result in the unintended consequence of reducing the systems resilience (Fiksel 2006). In that 2011 paper, I concluded that some of us keep resilience-theory and sustainability-science approaches separate and that we build on the distinctiveness of these approaches to achieve shared objectives. I developed these thoughts further in a keynote address at the first International Conference on Urban Sustainability and Resilience in November 2012 at University College, London. In the six conferences where I presented aspects of this proposition, there was active discussion of the issues with significant push back, but there was equal enthusiasm for delving further into the distinctiveness debate. This article is a first effort to bring this debate to a wider audience.

Scientists who have tried to merge these approaches include those whose ideas I greatly respect and who have made significant contributions (e.g., Chapin et al. 2009, Folke et al. 2010, Anderies et al. 2013). I do not presume to argue that I am right and they are wrong, but that an open and rich dialogue would benefit both those who want to combine the approaches and those who want to keep them separate. Although combining elements is productive in some cases, there are other situations where researchers must prioritize one approach and focus their energies accordingly. This dialogue would be especially useful for junior scholars who are crafting their individualized research approaches in the service of making the world a better, more enduring place to live.

A quick review of the burgeoning literature on resilience and sustainability reveals considerable variation in the definitions and uses of these concepts. Brand and Jax (2007) reviewed the multiple meanings of resilience, Hopwood et al. (2005) and Miller (2013) discussed alternate approaches to sustainability, and Fiksel (2006) brought an engineer's perspective into both terms. Brand and Jax (2007) further suggested that ambiguous, vague meanings hinder scientific progress because they are difficult concepts to apply (Thapa et al. 2010). I aim not to further parse these definitions, but to examine the negative and positive results of their conjunction.

In this article, I focus attention on areas where scientists might pursue resilience and sustainability in distinct ways: (1) the extent to which we can control the outcome of system change, (2) incorporation of stakeholder and community input, and (3) integration of lessons of the past and diverse cultural traditions into problem-solving approaches for the future. 
Table 1. Contrasting elements of adaptation and transformation.

\begin{tabular}{ll}
\hline \hline Adaptation & Transformation \\
\hline Incremental change & Major, potentially fundamental, change \\
Respond to shock & Action in anticipation of major stresses \\
Maintain previous order & Create new order, open ended \\
Build adaptive capacity & Reorder system dynamics \\
Emergent properties guide trajectory & Build agency, leadership, change agents \\
\hline
\end{tabular}

\section{ADAPTATION AND TRANSFORMATION AS CORE ACTIONS}

To distinguish between resilience and sustainability approaches, it is useful to contrast adaptation and transformation (see Table 1), which exhibit some parallel distinctions in their effort to deal with the risks associated with change and uncertainty (Leach et al. 2010, Brown and Westaway 2011, Kates et al. 2012).

Adaptation relates to the decision-making processes and actions undertaken to adjust a system to future shocks, stresses, or other changing conditions in a way that maintains essential system functioning (Nelson et al. 2007). It is understood that necessary changes to the system will be modest and incremental. Hence, adaptive strategies are relatively conservative: under the pressure of changing conditions, these strategies serve to maintain or return the system to the previous order or one similar to it. Adaptive strategies are often specific and local; they address a potential threat and associated vulnerability and adjust the system as a response to that threat.

Some theorists have noted the similarities of this process to specific resilience, for which one asks what conditions are resilient, and to what and for whom are they resilient. (Folke et al. 2010). A broader perspective on this strategy, analogous to general resilience, is one that advocates for attempts to enhance the adaptive capacity of the system to weather a wide range of potential shocks and stresses ( Nelson et al. 2007, Chapin et al. 2009, Brown and Westaway 2011). Resilience theorists argue that enhancing a system's adaptive capacity offers a pathway for maintaining system functioning (Gunderson and Holling 2002). The current political arena favors adaptation because it works to maintain the established order and address near-term problems. Citizens and their elected officials are more comfortable with adaptation because it appears less radical than transformation, which involves uncertain outcomes and the associated costs of system restructuring. Consequently, resilience approaches are popular in today's political arena.

Transformation implies a more pervasive and radical reorganization of the social-ecological system. Nelson and others (2007) define transformation as a fundamental alteration of a system once the current ecological, social, or economic conditions become untenable or are undesirable (see also Walker et al. 2004, 2006). Hence, the transformation of systems dynamics may be required or desired in situations where a major threat is envisioned, such as severe climate change, or where a system malfunction is recognized, such as the poverty trap immigrants move into many cities of the developing world (Thapa et al. 2010, Kates et al. 2012). Transformatory thinking can result from an enduring and increasing stress perceived as nearing a threshold or tipping point that could have dire implications for the system. Hence, the strategy is to act to allow the system to reconfigure itself by introducing a new set of dynamics that operate within specified desirable values over the long term. However, transformative actions involve taking substantial risks, often are seen as expensive, and have more uncertain outcomes than most adaptive actions. To the extent that transformative strategies are aimed at specific system changes or outcomes, they have much in common with sustainability-science approaches such as transition management (Rotmans et al. 2001, Loorbach 2010), in which projecting trajectories of change and making appropriate interventions are the objectives. These efforts benefit from enabling factors such as effective leaders who act as change agents, knowledge of the implications of probable outcomes, and the financial and institutional resources to enact the changes. Many sustainability advocates suggest that transformations are necessary to build a pathway to sustainability and urge their colleagues and students to take leadership roles (Hopwood et al. 2005, Leach et al. 2010, Wiek et al. 2011). However, to the extent that details about future states are left flexible and enhancing the robustness of the system and its governance is the goal, transformation actions can also be a part of a resilience approach (Olsson et al. 2006, Folke et al. 2010).

\section{RESILIENCE-THEORY AND SUSTAINABILITY- SCIENCE APPROACHES}

Resilience theory and sustainability science share many objectives and elements in their drive to understand system dynamics, enhance strategic competencies, and include diverse perspectives (Fiksel 2006, Lui et al. 2007, Leach et al. 2010, Wiek et al. 2011; see Table 2 for summary comparison).

Resilience is the capacity of a system to experience shocks while retaining function, structure, feedback capabilities, and therefore identity (Walker et al. 2006, Walker and Salt 2006). Resilience theory emphasizes that change is as normal a condition for socialecological systems as stability, and a system may exist in multiple stable states. The goal is to enable a system to respond to changing conditions so that there are minimal losses to the system and to its essential functioning. External shocks or emergent stresses pushing the system over a threshold may prompt the changing condition.

At the outset of a cycle of change, the end result it is not predetermined and may ultimately resemble the system's preexisting conditions or be different, i.e., regime shift. Because the outcome of the system moving through the adaptive cycle is not predetermined, the resilience theorist must be willing to take action based on incomplete knowledge of the impact of that action and with confidence that the emergent properties of the 
Table 2. Contrasting elements of resilience and sustainability.

\begin{tabular}{ll}
\hline \hline Resilience Theory Approach & Sustainability Science Approach \\
\hline Change is normal, multiple stable states & Envision the future, act to make it happen \\
Experience adaptive cycle gracefully & Utilize transition management approach \\
Origin in ecology, maintain ecosystem services & Origin in social sciences, society is flawed \\
Result of change is open ended, emergent & Desired results of change are specified in advance \\
Concerned with maintaining system dynamics & Focus is on interventions that lead to sustainability \\
Stakeholder input focused on desirable dynamics & Stakeholder input focused on desirable outcomes \\
\hline
\end{tabular}

new system will be desirable. With the strong connection of resilience theory to ecology and natural-resource management, there has been a tendency to judge outcomes that maintain conditions and the services produced by the preexisting system as a positive result, although it is recognized that some resilient systems are in an undesirable state and could be improved by change.

Prominent case studies by Resilience Alliance members have focused on changing biophysical ecosystem conditions in which humans play a role, but are not the primary indicators of system condition (see examples in Gunderson et al. 1995, Gunderson and Holling 2002, and Walker and Salt 2006). Discussions among resilience theorists have tackled the question of how to manage transformations within their framework (see Olsson et al. 2006), which has opened up the question of what aspects of the system are to be made resilient and what should be allowed to change. These normative questions have expanded the focus of the resilience theorists to include the social elements of the system and collaborations with stakeholders and other participants to make those decisions (see Xu and Marinova 2013 for bibliometric trends in resilience literature). The role of community deliberations is not simple because, theoretically, a resilience approach is not intended to choose among outcomes, but focus on system dynamics that might be favored over others. Hence, issues like increasing natural and social capital, preparing for cascading impacts of action, adjusting to mismatched cross-scale linkages, and moving the system out of undesirable basins of attraction become the goals of analysis and action (Walker et al. 2006, Folke et al. 2010).

Sustainability science seeks to address the major challenges facing society while ensuring that human well-being is undiminished and the basic Earth systems continue to operate. Its most widely cited definition comes from Our Common Future (Bruntland 1987:43, commonly referred to as the Bruntland report), which suggests that sustainable development "meets the needs of the present without compromising the ability of future generations to meet their own needs."

To specify the direction of desired changes, I join with those who define a sustainability pathway as one in which human well-being is enhanced, social equity is advanced, and environmental integrity is protected (Leach et al. 2010). With strong connections to politics, management, and development (see Bettencourt and Kaur 2011 for bibliometric analysis of field in the past three decades), sustainability scientists tend to be unsatisfied with the current order and advocate for more fundamental and often radical transformations to the system (Gibson 2006, Leach et al. 2010, Smith and Stirling 2010).
To transform society, it is necessary to engage with community members and stakeholders to (1) outline what is important to them through sustainability metrics, (2) project trajectories for their system, (3) identify desirable futures, and (4) formulate interventions that will lead to the desired, sustainable outcomes (National Research Council 1999, Robinson 2003, Wiek et al. 2012). Accepting this framework, transition management offers an operational model that emphasizes agency and power relations and resulting interventions that design, stimulate, and manage the trajectory of change (Rotmans et al. 2001, Loorbach 2010). Similar to a resilience approach, sustainability analyses understand the biophysical drivers and constraints on a system's future, but focus on and measure change in terms of human decisions, institutional dynamics, and shared attitudes (see case studies in Wiek et al. 2012). In most cases, the magnitude of change required to achieve sustainability suggests a transformation of the system; associated terminology implies that seeking sustainable outcomes is a journey (National Research Council 1999) or pathway (Leach et al. 2010) and that it is aspirational and requires iterations of improvements.

The strength of a sustainability approach is that it systematically examines future options, assigns values to those options via indicators, and customizes its strategies to attain those options. It rigorously integrates normative values and anticipatory thinking into a scientific framework (Clark and Dickson 2003, Swart et al. 2004). In contrast, the strength of a resilience approach is that it develops adaptive capacity and/or robustness into the system so that the system can gracefully weather the inevitable, but unspecified, system shocks and stressors. Resilience approach does not require predicting outcomes. Instead, it builds social and natural capital and enhances adaptive capacity to cope with unknown futures (Carpenter and Folke 2006, Folke et al. 2010). Simply put, sustainability prioritizes outcomes; resilience prioritizes process. I expect that students, professors, and practitioners may each incorporate my reflections on the two approaches differently, and I see that diversity as a strength for dealing with the future.

\section{MOVING FORWARD: INCREASING STRENGTH BY RETAINING DISTINCTIVENESS}

The following recommendations are aimed at students and young professionals who are still formulating their approach. These potential change agents of the coming generation must move forward to develop both resilience theory and sustainability science as frameworks for understanding.

To create tools for taking action, six domains deserve continued attention. The first three apply equally to both resilience and sustainability approaches. The final three are best pursued 
separately because they should develop in distinctive ways that derive strength and focus from their different underlying assumptions.

\section{Domains for action}

Domain 1: system dynamics

With both frameworks, it is fundamental to thoroughly understand the dynamics of the system, its feedback mechanisms, cross-scale linkages, cascading impacts, potential trade-offs, and to the extent possible, its alternate potential states and their implications on a human scale. This nexus is where much of the heavy lifting must be done.

\section{Domain 2: strategic competency}

It is necessary to understand how to transform ideas derived from science and other sources into meaningful action. This involves having strong strategic skills that promote effective communication, teamwork, and leadership, as well as the insight into the system dynamics to recognize aspects of its resilience and power relations that must be overcome to enable desired changes. Transforming knowledge into action will continue to be a central challenge of the coming generation (Cash et al. 2003).

\section{Domain 3: inclusiveness}

To value diverse perspectives, one must collaborate with other disciplines as well as engage stakeholders and the community to develop a shared understanding and a strong commitment to the endeavor. Procedures must be transparent and demonstrate respect for and empathy with the traditionally disadvantaged voices. Without broad input, decision making too often frames problems and potential solutions that serve to maintain the existing power structure and further disenfranchise the powerless (Leach et al. 2010).

\section{Domain 4: prioritize either outcomes or system dynamics}

The most fundamental difference for an aspiring resilience or sustainability scholar to consider is that the primary objective of a sustainability scientist is to identify specific, sustainable outcomes for the system and possible pathways to achieve these conditions, whereas a resilience scientist focuses on building a system's adaptive capacity to favorably respond to shocks and stresses without predetermining the specific outcome of the actions. Viewed in this way, sustainability science shares many elements with the design professions. The sustainability practitioner must possess the practical tools and intellectual confidence to suggest future conditions that will both work in the specific real-world context and exhibit the desired sustainability characteristics. On the other hand, the challenge facing the resilience theorist is to be able to reconfigure the dynamics of a system and enhance the capabilities of those who manage it so that together they are able to more effectively respond to previously experienced and yet-to-be experienced, but expectable, forces of change. These responses should be structured so that the system remains within desired limits or navigates change to a new, more desirable state.

Resilience theorists analyze ways in which adaptive capacity could be enhanced by avoiding scale mismatches (Cummings et al. 2006), involving robust community input, properly valuing ecosystem services, and building governing institutions that learn (Walker et al. 2006). In a resilient system, a more responsive, adaptive government works in concert with its environment. Sustainability's approach has sought not just to improve the way governments learn and respond, but to question whether governmental institutions must be dramatically transformed. For a sustainability practitioner, it would not be enough for governments to incorporate more knowledge in their decision making, but rather to anticipate future conditions and realign power relationships that frame the problems and possible solutions, all leading to the ultimate goal of socially just and enduring solutions.

\section{Domain 5: focus of community input}

Perhaps the biggest operational difference between the sustainability and resilience approaches is how practitioners incorporate the views and values of stakeholders and community members. Both approaches engage the community, but distinguishing the approaches might result in substantial enhancements.

In the case of resource management, a resilience approach assumes a coupled social-ecological system and seeks stakeholder input to maintain or enhance desired ecosystem services. Given the resilience objective of enhancing adaptive capacity, input would focus on the reorganization phase of the adaptive cycle so that when new system functioning is framed, participants' input identifies the relationships and qualities that are highly valued and those to be avoided. Resilience theory does not seek to control the outcomes of the adaptive cycle. It structures the reorganization and exploitation phases so that some relationships are favored and others discouraged. The ultimate goal is not to build adaptive capacity within just any system state, but enhance the likelihood that the new system will weather shocks, pass through the inevitable adaptive cycle gracefully, reduce serious vulnerabilities, and move system states from undesirable to desirable. The inclusion of normative value judgments as criteria for guiding the reorganization and exploitation phases does, in some ways, constrain the emergent quality of the new order, which in itself seems inconsistent with resilience assumptions. Many resilience theorists advocate this type of normative input, which may result in operations within the adaptive cycle that account for power relations, agency of actors, and hence outcomes that both theorists and stakeholders would judge as positive (Olsson et al. 2006).

For the sustainability practitioner, community and stakeholder input define the current condition of the system and areas that are unsustainable. From that baseline, desirable future scenarios and pathways are developed. Stakeholder and community input, along with sustainability-scientist expertise, thus coidentify desirable outcomes for the system, evaluate necessary trade-offs, and develop specific interventions that put the system on a sustainable pathway. Of course, to reach and maintain a sustainable state, the system must be able to withstand shocks, which may involve building the overall adaptive capacity of the system, i.e., general resilience, but adaptive capacity itself may or may not act to introduce or reinforce sustainable outcomes. In fact, many systems may be very resilient, i.e., have high adaptive capacity, but be judged undesirable. Examples are being in the poverty trap, being governed by fascists, or being unsustainable, as in the case of our current fossil-fuel consumption. Hence, in many cases, a sustainability change agent would identify the factor 
that has held the current system in an undesirable state and suggest ways to overcome that specific resilience while transitioning the system onto a sustainable pathway. Resilience theorists have recognized this need (Walker et al. 2004).

Practitioners of both persuasions should be able to lead a community to envision future scenarios and to assess the associated value implications so that selected scenarios reflect community values. However, sustainability practitioners must ensure that the planned interventions and eventual outcomes incorporate sustainable dynamics. To position sustainability outcomes as paramount, envision future conditions, and integrate normative values, sustainability practitioners need excellent communication, leadership, and strategic skills (Wiek et al. 2011).

\section{Domain 6: the past as a laboratory for innovations}

Both approaches examine past experiences for insights. However, subtly distinctive efforts would lead to more effective results. Historical insights should include examples from both modern and more distant times, and from Western and non-Western societies, and should be contextualized to place as well as examined for possible similarities. History, taken broadly, contains virtually limitless potential experiments with resource management, adaptive responses, participatory decision making, responses to climate change, introduction of new technologies, social attitudes, trade-offs, diverse social-ecological interactions, forms of organization, governance, and perhaps most fundamentally, humans' attitudes toward themselves, their surroundings, and their future.

Although these experiments offer a tremendous database for building adaptive capacity and transformability, they are underused by both resilience theorists and sustainability scientists. Both have built the passage of time into their theoretical frameworks as well as the importance of history in creating context, but neither has effectively incorporated historical knowledge or, more generally, a long-term perspective (e.g., Redman et al. 2004, Diamond 2005, Fisher et al. 2009, Schoon et al. 2011, Cooper and Sheets 2012). Just as resilience and sustainability practitioners have made poor use of history, those who do focus on the past and other cultures, such as historians, archaeologists, and anthropologists, have poorly framed their knowledge as useful to addressing today's challenges. A typical historical approach is to situate oneself in the present and look to what occurred in the past for an explanation of how we got to where we are, i.e., an attempt to understand the pathway to the present. However, for many, the present is flawed and what we want to know is what alternative systems might have been possible and how could social-ecological systems have been guided to yield better outcomes? We must find a way to reexamine the past and reconstruct the framework of alternatives and decisions faced at the time, and ask why alternative paths were not chosen or were chosen and failed.

Up to this point, my suggestions related to use of historical perspectives are similar for both resilience or sustainability. However, once again, the differences are in what one is actually trying to accomplish. The resilience theorist's focus should be on using the enormous database of changing conditions, stresses or shocks, the responses to them, and the respective outcomes. Hence, evidence from the past and from diverse societies can act as a huge compendium of case studies that may provide an improved basis for predicting the desirability of adaptive responses in advance. Adaptive responses tend to be formulated based on logic and contemporary experiences. I recommend that resilience scientists broaden the basis of that experience database and base the logic on far more examples and potential interactions.

Of course, historical knowledge is of interest to sustainability practitioners as well, particularly as they design interventions that they hope will put the system on a sustainable pathway. Sustainability advocates could use historical evidence to improve their judgment about what is possible. As suggested earlier, sustainability approaches often pursue more dramatic, transformative change. However, transformations by their very nature are more risky, being further from current conditions and often involving new sets of interactions and dynamics.

The past is a rich source of insight into the possible, the likely, and the unlikely. One must always add the caveat that, because every situation and context is unique and technology and many other elements have evolved over time, it is risky to oversimplify the past when designing the future. Although we must exert caution when using historical reasoning, we as humans have changed little physiologically or interpersonally in the past 10,000 years or more.

\section{CONCLUSION}

The history and archaeology of the past 10,000 years have shown countless examples of people, as individuals, small groups, and increasingly large organizational units, facing changing conditions, serious stresses, and unexpected shocks. Although the geographic scale of modern challenges appears to dwarf historical challenges, systemic shocks experienced by people in the past were just as daunting. Taking a big-picture perspective, people and societies have been amazingly successful in responding to challenges. By most objective measures, the human career to this point has been a great success!

If one takes a simple view of history, it is easy to argue that our society as it has developed will continue well into the future. This success has been achieved through adaptation and occasional transformations that, in virtually all cases, have exacerbated the divide between rich and poor and often led to further degradation of the environmental resources that both groups depend upon. Modest refinements or more efficient approaches to the challenges facing us will not reverse or alter this trajectory. Business as usual will perpetuate aspects of society we find socially undesirable and threaten the capacity of the Earth's systems. We need to implement more sweeping, transformative changes in the way we interact with each other as well as with the surrounding built and natural environment.

If we need to transform our social-ecological systems to achieve a resilient and/or sustainable world, then we also need scientists to change their way of doing business. Unsurprisingly, personal and societal values influence scientists as they incorporate ethical ideals and approaches into their work. In my own research into future trajectories for urbanization, the ideas of sustainable cities and resilient cities have strong followings. In fact, it has been often suggested to me that for cities to be sustainable they must be resilient. Others argue that sustainable cities of the future will be "smart" cities (Harrison et al. 2010, Calabrese et al. 2011). Both 
approaches have merits, and combining them may be the best option. However, a closer look at the mechanics proposed for smart cities, increasing energy and material efficiencies through highly interconnected information and decision systems, suggests an inflexibility and extreme hypercoherence that resilience theorists have often warned against (Holling and Gunderson 2002). Smart cities are unlikely to be more just cities, thus failing to achieve a key sustainability indicator. Urban planners and decision makers should assess the potential benefits to each approach, working through their implications in a holistic and consistent way. Toward that end, we must rigorously pursue adoption of distinct resilience and sustainability approaches, as well as combinations of the two, allowing each approach to contribute in ways that reflect its strengths.

\section{Responses to this article can be read online at:} http://www.ecologyandsociety.org/issues/responses. php/6390

\section{Acknowledgments:}

This article has benefited from ideas drawn from and developed in collaboration with many colleagues who are themselves both prominent resilience theorists and sustainability scientists. Among those who read earlier drafts of this article and provided crucial insights were Arnim Wiek, Andy Stirling, Katrina Brown, Hallie Eakin, Neil Adger, Robert Gibson, and two anonymous reviewers.

\section{LITERATURE CITED}

Anderies, J. M., C. Folke, B. Walker, and E. Ostrom. 2013. Aligning key concepts for global change policy: robustness, resilience, and sustainability. Ecology and Society 18(2): 8. http:// dx.doi.org/10.5751/ES-05178-180208

Bettencourt, L. M. A., and J. Kaur. 2011. Evolution and structure of sustainability science. Proceedings of the National Academy of Sciences of the United States of America 108(49):19540-19545. http://dx.doi.org/10.1073/pnas.1102712108

Brand, F. S., and K. Jax. 2007. Focusing the meaning(s) of resilience: resilience as a descriptive concept and a boundary object. Ecology and Society 12(1): 23. [online] URL: http://www. ecologyandsociety.org/vol12/iss1/art23/

Brown, K., and E. Westaway. 2011. Agency, capacity, and resilience to environmental change: lessons from human development, well-being, and disasters. Annual Review of Environment and Resources 36:321-342. http://dx.doi.org/10.1146/ annurev-environ-052610-092905

Bruntland, G. H. 1987. Our common future: report of the 1987 World Commission on Environment and Development. Oxford University Press, Oxford, UK.

Calabrese, F., M. Colonna, P. Lovisolo, D. Parata, and C. Ratti. 2011. Real-time urban monitoring using cell phones: a case study in Rome. Intelligent Transportation Systems, IEEE Transaction on 12(1):141-151. http://dx.doi.org/10.1109/TITS.2010.2074196
Carpenter, S. R., and C. Folke. 2006. Ecology for transformation. Trends in Ecology \& Evolution 21(6):309-315. http://dx.doi. org/10.1016/j.tree.2006.02.007

Cash, D. W., W. C. Clark, F. Alcock, N. M. Dickson, N. Eckley, D. H. Guston, J. Jager, and R. B. Mitchell. 2003. Knowledge systems for sustainable development. Proceedings of the National Academy of Sciences of the United States of America USA 100 (14):8086-8091. http://dx.doi.org/10.1073/pnas. 1231332100

Chapin, F. S., III, G. P. Kofinas, and C. Folke, editors. 2009. Principles of ecosystem stewardship: resilience-based natural resource management in a changing world. Springer, New York, New York, USA.

Clark, W. C., and N. M. Dickson. 2003. Sustainability science: the emerging research program. Proceedings of the National Academy of Sciences of the United States of America 100 (14):8059-8061. http://dx.doi.org/10.1073/pnas.1231333100

Cooper, J., and P. Sheets, eds. 2012. Surviving sudden environmental change: answers from archaeology. University Press of Colorado, Boulder, Colorado, USA.

Cumming, G. S., D. H. M. Cumming, and C. L. Redman. 2006. Scale mismatches in social-ecological systems: causes, consequences, and solutions. Ecology and Society 11(1): 14. [online] URL: http://www.ecologyandsociety.org/vol11/iss1/ art14/

Diamond, J. 2005. Collapse: how societies choose to fail or succeed. Viking, New York, New York, USA.

Fiksel, J. 2006. Sustainability and resilience: toward a systems approach. Sustainability: Science, Practice, \& Policy 2(2):14-21.

Fisher, C. T., J. B. Hill, and G. M. Feinman, editors. 2009. The archaeology of environmental change: socionatural legacies of degradation and resilience. University of Arizona Press, Tucson, Arizona, USA.

Folke, C., S. R. Carpenter, B. Walker, M. Scheffer, T. Chapin, and J. Rockström. 2010. Resilience thinking: integrating resilience, adaptability and transformability. Ecology and Society 15(4):20. [online] URL: http://www.ecologyandsociety.org/voll5/iss4/ $\underline{\operatorname{art} 20}$

Gibson, R. B. 2006. Sustainability assessment: basic components of a practical approach. Impact Assessment and Project Appraisal 24(3):170-182. http://dx.doi.org/10.3152/147154606781765147

Gunderson, L. H., and C. S. Holling, editors. 2002. Panarchy: understanding transformations in human and natural systems. Island Press, Washington, D.C., USA.

Gunderson, L. H., C. S. Holling, and S. S. Light, editors. 1995. Barriers \& bridges to the renewal of ecosystems and institutions. Columbia University Press, New York, New York, USA.

Harrison, C., B. Eckman, R. Hamilton, P. Hartswick, J. Kalagnanam, J. Paraszczak, and P. Williams. 2010. Foundations for smarter cities. IBM Journal of Research and Development. 54 (4):1-16. http://dx.doi.org/10.1147/JRD.2010.2048257

Holling, C. S., and L. H. Gunderson. 2002. Resilience and adaptive cycles. Pages 25-62 in L. H. Gunderson and C. S. Holling, 
editors. Panarchy: understanding transformations in human and natural systems. Island Press, Washington, D.C., USA.

Hopwood, B., M. Mellor, and G. O’Brien. 2005. Sustainable development: mapping different approaches. Sustainable Development 13(1):38-52. http://dx.doi.org/10.1002/sd.244

Kates, R. W., W. C. Clark, R. Corell, J. M. Hall, C. C. Jaeger, I. Lowe, J. J. McCarthy, H. J. Schellnhuber, B. Bolin, N. M. Dickson, S. Faucheux, G. C. Gallopin, A. Grübler, B. Huntley, J. Jäger, N. S. Jodha, R. E. Kasperson, A. Mabogunje, P. Matson, H. Mooney, B. Moore III, T. O'Riordan, and U. Svedin. 2001. Environment and development. Sustainability science. Science 292 (5517):641-642. http://dx.doi.org/10.1126/science.1059386

Kates, R. W., W. R. Travis, and T. J. Wilbanks. 2012. Transformational adaptation when incremental adaptations to climate change are insufficient. Proceedings of the National Academy of Sciences of the United States of America 109 (19):7156-7161. http://dx.doi.org/10.1073/pnas.1115521109

Leach, M., I. Scoones, and A. Stirling. 2010. Dynamic sustainabilities: technology, environment, social justice. Earthscan, London, UK.

Loorbach, D. 2010. Transition management for sustainable development: a prescriptive, complexity-based governance framework. Governance: An International Journal of Policy, Administration, and Institutions 23(1):161-183. http://dx.doi. org/10.1111/j.1468-0491.2009.01471.x

Lui, J., T. Dietz, S. R. Carpenter, M. Alberti, C. Folke, E. Moran, A. N. Pell, P. Deadman, T. Kratz, J. Lubchenco, E. Ostrom, Z. Ouyang, W. Provencher, C. L. Redman, S. H. Schneider, and W. W. Taylor. 2007. Complexity of coupled human and natural systems. Science 317(5844):1513-1516. http://dx.doi.org/10.1126/ science.1144004

Miller, T. R. 2013. Constructing sustainability science: emerging perspectives and research trajectories. Sustainability Science 8 (2):279-293. http://dx.doi.org/10.1007/s11625-012-0180-6

Miller, T. R., T. Muñoz-Erickson, and C. L. Redman. 2011. Transforming knowledge for sustainability: towards adaptive academic institutions. International Journal of Sustainability in Higher Education 12(2):177-192. http://dx.doi.org/10.1108/1467$\underline{6371111118228}$

National Research Council. 1999. Our common journey: a transition toward sustainability. National Research Council, Washington, D.C., USA.

Nelson, D. R., W. N. Adger, and K. Brown. 2007. Adaptation to environmental change: contributions of a resilience framework. Annual Review of Environment and Resources 32:395-419. http:// dx.doi.org/10.1146/annurev.energy.32.051807.090348

Olsson, P., L. H. Gunderson, S. R. Carpenter, P. Ryan, L. Lebel, C. Folke, and C. S. Holling. 2006. Shooting the rapids: navigating transitions to adaptive governance of social-ecological systems. Ecology and Society 11(1): 18. [online] URL: http://www. ecologyandsociety.org/vol11/iss1/art18/

Redman, C. L. 2005. Resilience theory in archaeology. American Anthropologist 107(1):70-77. http://dx.doi.org/10.1525/aa.2005.107.1.070
Redman, C. L. 2013. Transforming the silos: Arizona State University's School of Sustainability. Pages 229-239 in P. F. Barlett and G. W. Chase, editors. Sustainability in higher education: stories and strategies for transformation. M.I.T. Press, Cambridge, Massachusetts, USA.

Redman, C. L., S. R. James, P. Fish, and J. D. Rogers, editors. 2004. The archaeology of global change: the impact of humans on their environment. Smithsonian Books, Washington, D.C., USA.

Redman, C. L., and A. P. Kinzig. 2003. Resilience of past landscapes: resilience theory, society, and the longue durée.

Conservation Ecology 7(1): 14. [online] URL: http://www. consecol.org/vol7/iss1/art14/

Redman, C. L., and A. Wiek. 2013. Sustainability as a transformation in education. Pages 214-222 in L. F. Johnston, editor. Higher education for sustainability: cases, challenges, and opportunities from across the curriculum. Routledge, New York, New York, USA.

Robinson, J. 2003. Future subjunctive: backcasting as social learning. Futures 35(8):839-856. http://dx.doi.org/10.1016/ S0016-3287(03)00039-9

Rotmans, J., R. Kemp, and M. van Asselt. 2001. More evolution than revolution: transition management in public policy. Foresight 3(1):15-31. http://dx.doi.org/10.1108/14636680110803003

Schoon, M., C. Fabricius, J. M. Anderies, and M. Nelson. 2011. Synthesis: vulnerability, traps, and transformations-long-term perspectives from archaeology. Ecology and Society 16(2): 24. [online] URL: http://www.ecologyandsociety.org/vol16/iss2/ $\underline{\operatorname{art} 24 l}$

Smith, A., and A. Stirling. 2010. The politics of social-ecological resilience and sustainable socio-technical transitions. Ecology and Society 15(1): 11. [online] URL: http://www.ecologyandsociety. org/vol15/iss1/art11/

Swart, R. J., P. Raskin, and J. Robinson. 2004. The problem of the future: sustainability science and scenario analysis. Global Environmental Change 14(2):137-146. http://dx.doi.org/10.1016/ j.gloenvcha.2003.10.002

Thapa, S., F. Marshall, and S. Stagl. 2010. Understanding periurban sustainability: the role of the resilience approach. STEPS Working Paper 38. STEPS Centre, Brighton, UK.

Walker, B., L. H. Gunderson, A. P. Kinzig, C. Folke, S. R. Carpenter, and L. Schultz. 2006. A handful of heuristics and some propositions for understanding resilience in social-ecological systems. Ecology and Society 13(1): 13. [online] URL: http://www. ecologyandsociety.org/vol11/iss1/art13/

Walker, B., C. S. Holling, S. R. Carpenter, and A. Kinzig. 2004. Resilience, adaptability and transformability in social-ecological systems. Ecology and Society 9(2): 5. [online] URL: http://www. ecologyandsociety.org/vo19/iss2/art5/

Walker, B., and D. Salt. 2006. Resilience thinking: sustaining ecosystems and people in a changing world. Island Press, Washington, D.C., USA.

Wiek, A., B. Ness, P. Schweizer-Ries, F. S. Brand, and F. Farioli. 2012. From complex systems analysis to transformational change: 
a comparative appraisal of sustainability science projects. Sustainability Science 7(1 suppl):5-24. http://dx.doi.org/10.1007/ $\underline{\text { s11625-011-0148-y }}$

Wiek, A., L. Withycombe, and C. L. Redman. 2011. Key competencies in sustainability: a reference framework for academic program development. Sustainability Science 6 (2):203-218. http://dx.doi.org/10.1007/s11625-011-0132-6

$\mathrm{Xu}$, L., and D. Marinova. 2013. Resilience thinking: a bibliometric analysis of socio-ecological research. Scientometrics 96(3):911-927. http://dx.doi.org/10.1007/s11192-013-0957-0 